\title{
The Parenting to Reduce Adolescent Depression and Anxiety Scale: Assessing parental concordance with parenting guidelines for the prevention of adolescent depression and anxiety disorders
}

\author{
Mairead C Cardamone-Breen ${ }^{1}$, Anthony F Jorm ${ }^{2}$, Katherine A Lawrence $^{1}$ ， Andrew J Mackinnon ${ }^{2,3}$, Marie B H \\ Yap ${ }^{\text {Corresp. } 1,2}$ \\ ${ }^{1}$ School of Psychological Sciences, Monash Institute of Cognitive and Clinical Neurosciences, Monash University, Melbourne, Victoria, Australia \\ 2 Melbourne School of Population and Global Health, University of Melbourne, Melbourne, Victoria, Australia \\ 3 Black Dog Institute, University of New South Wales, Sydney, New South Wales, Australia \\ Corresponding Author: Marie B H Yap \\ Email address: marie.yap@monash.edu
}

Background. Despite substantial evidence demonstrating numerous parental risk and protective factors for the development of adolescent depression and anxiety disorders, there is currently no single measure that assesses these parenting factors. To address this gap, we developed the Parenting to Reduce Adolescent Depression and Anxiety Scale (PRADAS) as a criterion-referenced measure of parental concordance with a set of evidence-based parenting guidelines for the prevention of adolescent depression and anxiety disorders. In this paper, we used a sample of Australian parents of adolescents to: 1) validate the PRADAS as a criterion-referenced measure; 2) examine parental concordance with the guidelines in the sample; and 3) examine correlates of parental concordance with the guidelines.

Methods. 711 parents completed the PRADAS, as well as two established parenting measures, and parent-report measures of adolescent depression and anxiety symptoms. 660 adolescent participants (aged 12 to 15) also completed the symptom measures. Concordance with the guidelines was assessed via nine subscale scores and a total score. Reliability of the scores was assessed with an estimate of the agreement coefficient, as well as 1-month test-retest reliability. Convergent validity was examined via correlations between the scale and two established parenting measures.

Results. One proposed subscale was removed from the final version of the scale, resulting in a total of eight subscales. Reliability was high for the total score, and acceptable to high for seven of the eight subscales. One-month test-retest reliability was acceptable to high for the total score. Convergent validity was supported by moderate to high correlations with two established measures of parenting. Overall, rates of parental concordance with the guidelines were low in our sample. Higher scores were associated with being female and higher levels of parental education. Greater parental concordance with the guidelines was associated with fewer symptoms of depression and anxiety in adolescent participants.

Discussion. This initial validation study provides preliminary support for the reliability and validity of the PRADAS. The scale has potential for use in both clinical and research settings. It may be used to identify parents' strengths and potential targets for intervention, and as an outcome measure in studies of preventive parenting interventions. 
1 The Parenting to Reduce Adolescent Depression and Anxiety Scale: Assessing parental

2 concordance with parenting guidelines for the prevention of adolescent depression and

3 anxiety disorders

4

5 Mairead C Cardamone-Breen ${ }^{1}$, Anthony F Jorm ${ }^{2}$, Katherine A Lawrence ${ }^{1}$, Andrew J

6 Mackinnon ${ }^{2,3}$, Marie B H Yap ${ }^{1,2}$

$7{ }^{1}$ School of Psychological Sciences, Monash Institute of Cognitive and Clinical Neurosciences,

8 Monash University, Melbourne, Victoria, Australia.

$9{ }^{2}$ Melbourne School of Population and Global Health, University of Melbourne, Melbourne,

10 Victoria, Australia.

$11{ }^{3}$ Black Dog Institute, University of New South Wales, Sydney, New South Wales, Australia.

14 Corresponding Author:

15 Dr Marie Yap

16 School of Psychological Sciences, Monash University, 18 Innovation Walk, Clayton, VIC, 3800, 17 Australia.

18 Email address: marie.yap@monash.edu 


\section{Abstract}

20 Background. Despite substantial evidence demonstrating numerous parental risk and protective

21 factors for the development of adolescent depression and anxiety disorders, there is currently no

22 single measure that assesses these parenting factors. To address this gap, we developed the

Parenting to Reduce Adolescent Depression and Anxiety Scale (PRADAS) as a criterion-

24 referenced measure of parental concordance with a set of evidence-based parenting guidelines

25 for the prevention of adolescent depression and anxiety disorders. In this paper, we used a

sample of Australian parents of adolescents to: 1) validate the PRADAS as a criterion-referenced measure; 2) examine parental concordance with the guidelines in the sample; and 3) examine correlates of parental concordance with the guidelines.

Methods. 711 parents completed the PRADAS, as well as two established parenting measures, and parent-report measures of adolescent depression and anxiety symptoms. 660 adolescent

31 participants (aged 12 to 15 ) also completed the symptom measures. Concordance with the

32 guidelines was assessed via nine subscale scores and a total score. Reliability of the scores was assessed with an estimate of the agreement coefficient, as well as 1-month test-retest reliability.

34 Convergent validity was examined via correlations between the scale and two established 35 parenting measures.

Results. One proposed subscale was removed from the final version of the scale, resulting in a total of eight subscales. Reliability was high for the total score, and acceptable to high for seven of the eight subscales. One-month test-retest reliability was acceptable to high for the total score.

39 Convergent validity was supported by moderate to high correlations with two established measures of parenting. Overall, rates of parental concordance with the guidelines were low in our

41 sample. Higher scores were associated with being female and higher levels of parental education. 
42 Greater parental concordance with the guidelines was associated with fewer symptoms of 43 depression and anxiety in adolescent participants.

44 Discussion. This initial validation study provides preliminary support for the reliability and

45 validity of the PRADAS. The scale has potential for use in both clinical and research settings. It

46 may be used to identify parents' strengths and potential targets for intervention, and as an

47 outcome measure in studies of preventive parenting interventions. 


\section{Introduction}

Depression and anxiety disorders are among the largest contributors to global burden of disease, and are leading causes of disability in young people (Kessler et al., 2007; Mathews et al., 2011; Patel et al., 2007). These disorders have peak onset early in life, with approximately half of all cases emerging by age 14, and $75 \%$ by 24 years (Kessler et al., 2005). Early onset of depression and anxiety is associated with a cascade of negative long-term sequelae (e.g., Copeland et al., 2009; Dekker et al., 2007; Woodward \& Fergusson, 2001), leading to recognition that prevention of these disorders early in life is a global healthcare priority (Patel et al., 2007).

Existing research has demonstrated numerous risk and protective factors for the development of depression and anxiety early in life, many of which are shared between the disorders. The overlap of risk factors and high degree of comorbidity has led to the recommendation of a transdiagnostic preventive approach (Garber, 2006). Many risk factors are not modifiable (e.g., female gender, genetic disposition; Garber, 2006; Mathew et al., 2011; Rapee et al., 2009; Van Voorhees et al., 2008), or are difficult to intervene with at an individual level (e.g., socioeconomic status, family history of mental illness; Garber, 2006; Mathew et al., 2011; Van Voorhees et al., 2008). However, a number of identified factors involve the family environment, or can be detected and responded to by parents. For example, inter-parental conflict, over-involvement, parental aversiveness, and lack of family support have been shown to

67 increase risk (Hankin, 2006; Rapee, 2012; Rapee, Schniering \& Hudson, 2009; Van Voorhees et al., 2008; Yap et al., 2014a); whereas parental warmth, family connectedness, and autonomy granting reduce risk (Van Voorhees et al., 2008; Yap et al., 2014a). Thus, targeting specific risk and protective factors that are within parents' control is likely to be effective in preventing 
71 depression and anxiety in young people. Consideration of family and parenting factors in the

72 prevention of depression and anxiety has been recognised as a key research translation priority

73 (Avenevoli \& Merikangas, 2006; Fisak et al., 2011; Restifo \& Bögels, 2009). Promisingly, a

74 growing body of evidence supports the efficacy of preventive parenting interventions for

75 reducing risk of mental illness in children and adolescents (e.g., Sandler et al., 2011;

76 Siegenthaler, Munder, \& Egger, 2012; Yap et al., 2016).

To translate research evidence related to the role of parenting in the prevention of

adolescent depression and anxiety, a set of guidelines were developed for parents of adolescents:

79 "How to Prevent Depression and Clinical Anxiety in Your Teenager: Strategies for Parents"

80 (henceforth the Guidelines; Parenting Strategies Program, 2013;

81 www.parentingstrategies.net/depression). The Guidelines were developed through a two-phase

82 process involving: 1) a systematic review of parental risk and protective factors for adolescent

83 depression and anxiety (Yap et al., 2014a); and 2) a Delphi expert consensus study to establish

84 parenting strategies that are important for the prevention of depression and anxiety disorders in

85 adolescents (Yap et al., 2014b). The Guidelines include 190 practical parenting strategies,

86 organised under 11 topics: you can reduce your child's risk of depression and anxiety problems;

87 establish and maintain a good relationship with your teenager; be involved and support

88 increasing autonomy; establish family rules and consequences; minimise conflict in the home;

89 encourage supportive relationships; encourage good health habits; help your teenager deal with

90 problems; help your teenager to deal with anxiety; encourage professional help-seeking when

91 needed; and don't blame yourself.

92 Despite the large body of research demonstrating the importance of parenting factors,

93 there is currently no single measure that specifically assesses the range of parenting factors 
94 shown to influence the development of depression and anxiety in adolescents. Some factors, such

95 warmth, control, and aversiveness, have been extensively researched using widely-used

96 measures (e.g., the Parental Bonding Instrument, Parker, Tupling \& Brown, 1979; the EMBU

97 [Egna Minnem av Barndoms Uppfostram], Perris et al., 1980; the Children's Report of Parental

98 Behavior Inventory, Schaefer, 1965). However, other factors (e.g., encouraging sociability,

99 encouraging good health habits) have limited research and no validated measures. In order to

100 effectively target the range of parenting risk and protective factors in preventive interventions, a

101 valid measure to assess these factors is needed. To address this gap, the current paper describes

102 the development and validation of the Parenting to Reduce Adolescent Depression and Anxiety

103 Scale (PRADAS) - a parent-report measure of parenting practices against the recommendations

104 in the Guidelines. As the Guidelines recommend specific, defined strategies, we developed the

105 scale as a criterion-referenced measure. In contrast to commonly used norm-referenced tests, in

106 which an individual's performance is compared with that of others, criterion-referenced tests

107 assess knowledge or skills against defined domains of content (Hambleton \& Rogers, 1990).

108 These tests are used to determine whether an individual has reached a pre-defined level of

109 competence or mastery of a skill (Hambleton \& Rogers, 1990). Norm-referenced tests are unable

110 to provide this information, hence are not appropriate when this is the purpose of assessment.

111 Based on the research informing the Guidelines, higher levels of parental concordance with the

112 Guidelines are expected to be protective against adolescent depression and anxiety disorders.

\section{Aims and hypotheses}

114 In this paper, we used a sample of Australian parents of adolescents aged 12 to 15 to: 1 )

115 validate the newly developed PRADAS as a criterion-referenced measure of parental

116 concordance with the Guidelines; 2) examine levels of parental concordance with the Guidelines; 
117 and 3) examine correlates of parental concordance with the Guidelines. We examined the

118 reliability and validity of the scale to fulfil the first aim. Reliability was assessed via an estimate

119 of the agreement coefficient, as well as 1-month test-retest reliability. Validity of the scale was

120 determined based on its face validity and convergent validity indicators. Convergent validity was

121 assessed via correlations between the scale and two previously validated measures of parenting:

122 the Inventory of Parent and Peer Attachment (IPPA) and the Emotions as a Child scale (EAC).

123 As these measures each have some overlapping content with our scale, we predicted at least

124 moderate correlations. We predicted positive correlations with the subscales assessing positive

125 parenting practices, and negative correlations with the subscales assessing undesirable parenting

126 practices. We also expected small to moderate correlations between the nine PRADAS subscales

127 and moderate to high correlations between the subscale scores and the total score. Finally, we

128 explored the correlates of parental Guidelines concordance with participant characteristics (e.g.,

129 demographics, mental health history, adolescent depression and anxiety symptoms). We

130 predicted small correlations between parental Guidelines concordance and symptoms of

131 depression and anxiety in adolescent participants. Examination of other correlates were

132 exploratory in nature, hence no hypotheses were specified.

Methods

\section{Participants and procedures}

Participants were parent-adolescent dyads participating in one of two randomised

136 controlled trials (RCTs) of online parenting interventions aimed at preventing adolescent

137 depression and anxiety disorders. Eligible participants were parents or primary caregivers of an

138 adolescent aged 12 to 15 years, who resided in Australia and had regular internet access. No

139 exclusion criteria were specified. Parent participation was not dependent on adolescent 
140 participation; as such, parents could participate without their child. Only one parent-adolescent

141 dyad per family was eligible to participate. Recruitment was via online parenting networks,

142 social media, university networks, mental health organisations, and schools across Australia.

143 Ethics approval was obtained from the Monash University Human Research Ethics Committee

144 (approval numbers CF14/3886 - 2014002023 and CF14/3887 - 2014002024).

145 Parent participants self-selected by responding to advertisements and registering and

146 providing consent for themselves and their adolescent via the trial websites. Parents and

147 adolescents were provided with participant explanatory statements, detailing participation

148 requirements, privacy, and standard limits to confidentiality (e.g., disclosure of risk of harm to

149 self or others, child abuse). A member of the research team called adolescent participants to

150 explain the study and obtain their verbal assent. Adolescents who agreed to participate were

151 guided through their online baseline assessment over the phone, which included the child-report

152 version of the Spence Children's Anxiety Scale (SCAS) and Short Mood and Feelings

153 Questionnaire (SMFQ). Assistance to complete the measures was provided by the researcher

154 where necessary (e.g., in the case of learning disabilities). Adolescents were reimbursed for their

155 participation with an e-voucher. Following submission of the adolescent baseline assessment, an

156 automated email was sent to the parent participant containing the link to their baseline

157 assessment. Parent participants completed the PRADAS, and the parent-report versions of the

158 IPPA, EAC, SCAS, and SMFQ.

159 The two RCTs from which participants were drawn assessed similar interventions (i.e., a

160 brief and intensive version of the same online parenting program) and targeted similar

161 populations. Further, data used in the current paper was collected prior to any intervention being

162 received. It was therefore deemed acceptable to combine baseline data for the purposes of this 
163 paper. Demographic characteristics of participants from the two samples were compared to

164 assess for significant differences on key variables. There were no significant differences between

165 samples for the following variables: parent or child age; parent or child gender; parent

166 employment status; parent marital status; parent-child relationship (i.e., mother/father/other);

167 parent- or child- report scores on the SCAS or SMFQ; or total score on the PRADAS (all $p$ s >

168 .05). Significant differences were found for three demographic characteristics: 1) percentage of

169 parents speaking a language other than English (8.6\% in sample 1 vs. $15.8 \%$ in sample $2, \chi^{2}[1$,

$170 N=711]=8.62, p=.003) ; 2$ ) highest parent qualification, with a greater number of participants

171 in sample 1 having post-graduate qualifications (32.9\% vs. 24.9\%) and more parents in sample 2

172 having secondary school (year 7 to 12 ) qualifications $(13.9 \%$ vs. $7.7 \%), \chi^{2}[5, N=711]=15.75$,

$173 p=.008$; and 3) state of residence, with more participants in sample 2 residing in Victoria

$174\left(86.1 \%\right.$ vs. $\left.21.4 \%, \chi^{2}[7, N=711]=316.63, p<.001\right)$. As these variables were not outcomes, nor

175 expected to significantly affect results, we opted to combine the samples in order to attain a

176 larger and more diverse sample of parents in Australia.

177 A total of 350 and 361 parents registered and completed baseline assessments for the two

178 trials respectively. The final sample therefore comprised 711 parents. Most parents were female

$179(89.5 \%)$, with a mean age of 45.15 years $(S D=5.66) .660$ adolescents also consented to

180 participate and completed baseline assessments. Adolescents had a mean age of 13.66 years $(S D$

$181=1.05)$ and $47.3 \%$ were female. Table 1 presents additional participant demographic

182 characteristics. 
183 Table 1

184 Descriptive Statistics for Parent and Child Demographic Characteristics

\begin{tabular}{|c|c|c|}
\hline Parent/child characteristic & $N$ & $\%$ \\
\hline \multicolumn{3}{|l|}{ Parent relationship to child } \\
\hline Mother & 631 & 88.7 \\
\hline Father & 73 & 10.3 \\
\hline Grandmother & 2 & 0.3 \\
\hline Step-mother & 2 & 0.3 \\
\hline Step-father & 1 & 0.1 \\
\hline Aunt & 1 & 0.1 \\
\hline Guardian & 1 & 0.1 \\
\hline \multicolumn{3}{|l|}{ Parent relationship status } \\
\hline Married/defacto & 548 & 77.1 \\
\hline Separated/divorced & 120 & 16.9 \\
\hline Single & 37 & 5.2 \\
\hline Widowed & 6 & 0.8 \\
\hline \multicolumn{3}{|l|}{ Family situation } \\
\hline Intact family, child living with both parents & 486 & 68.5 \\
\hline Separated parents, shared care & 71 & 10.0 \\
\hline Child living with one parent (participant) & 132 & 18.6 \\
\hline Child living with one parent (not participant) & 9 & 1.3 \\
\hline Other & 12 & 1.7 \\
\hline \multicolumn{3}{|l|}{ Parent employment status } \\
\hline Working full time & 319 & 44.9 \\
\hline Working part time & 309 & 43.5 \\
\hline Unemployed & 83 & 11.7 \\
\hline Studying (full or part time) & 133 & 18.7 \\
\hline \multicolumn{3}{|l|}{ Parent education level } \\
\hline Secondary school year 7 to 12 & 77 & 10.8 \\
\hline Trade/apprenticeship & 7 & 1.0 \\
\hline TAFE certificate/other technical qualification & 70 & 9.8 \\
\hline Diploma & 126 & 17.7 \\
\hline Bachelor degree & 226 & 31.8 \\
\hline Postgraduate & 205 & 28.8 \\
\hline Language other than English spoken at home & 87 & 12.2 \\
\hline \multicolumn{3}{|l|}{ State of residence } \\
\hline Victoria & 386 & 54.3 \\
\hline New South Wales & 120 & 16.9 \\
\hline Queensland & 78 & 11.0 \\
\hline Tasmania & 54 & 7.6 \\
\hline South Australia & 25 & 3.5 \\
\hline Australian Capital Territory & 25 & 3.5 \\
\hline Western Australia & 22 & 3.1 \\
\hline Northern Territory & 1 & 0.1 \\
\hline
\end{tabular}

185 Note. $\mathrm{TAFE}=$ Technical and Further Education. 
186 Measures

The Parenting to Reduce Adolescent Depression and Anxiety Scale (PRADAS). As

discussed, the PRADAS was developed as a criterion-referenced measure of parental

concordance with the Guidelines. The scale therefore assesses current parenting practices against

the highest-quality evidence for parental risk and protective factors for adolescent depression and

anxiety. The scale also forms part of two newly developed individually-tailored online parenting

interventions which are currently being evaluated in two RCTs (trial registrations available at:

https://www.anzctr.org.au/Trial/Registration/TrialReview.aspx?ACTRN=12615000247572,

194 https://www.anzctr.org.au/Trial/Registration/TrialReview.aspx?id=368274).

(Hambleton \& Rogers, 1990). The consensus of experts on the topic is one suggested way of

comprehensively revised during multiple workshops by authors M.C.B., M.Y., A.J., and K. L.

199 Two of the authors (M.Y. and A.J.) were authors of the Guidelines, as well as a number of systematic reviews on the role of parenting in the prevention of child and adolescent depression and anxiety (e.g., Yap et al., 2016; Yap \& Jorm, 2015; Yap et al., 2014a). These authors also prevention of adolescent alcohol misuse (Yap et al., 2011; Yap et al., 2015). The remaining

The original version of the scale included 79 items, across nine subscales (6-12 items each), corresponding to the sections of the Guidelines. The first and last sections of the 
209 Guidelines were not included in the scale, as they provide psychoeducation rather than specific

210 parenting recommendations. Table 2 presents a summary of the PRADAS subscales, Guideline

211 topics, and risk/protective factors assessed in each. Most questions relate to a specific parenting

212 behaviour recommended in the Guidelines (e.g., eating dinner together as a family), assessed on

213 a Likert-type frequency scale (e.g., never, rarely, sometimes, often). Other questions relate to

214 hypothetical situations (e.g., noticing a persistent change in the adolescent's behaviour), and

215 enquire how likely a parent is to take certain actions (e.g., very unlikely, unlikely, likely, very

216 likely). In an attempt to reduce response bias, twenty-six items were negatively worded or false-

217 positive questions (e.g., the opposite behaviour to the recommendation in the Guidelines).

218 Supplemental File 1 contains the scale items.

219 Face validity. The scale was designed to have face validity, based on the opinion of the 220 developing authors. This was confirmed via consultation with a reference group of parents of 221 adolescents (see below).

Consultation with target-end users. To ensure acceptability of the measure to target-end users, we consulted a reference group of 22 parents (19 mothers, 3 fathers) of adolescents aged 11 to 18 years. Reference group parents were recruited via staff newsletters at Monash University and the University of Melbourne, local school newsletters, and social media. Parents attended one of three repeated focus group workshops ( $n=7$ to 8 per workshop), during which they were shown a draft of the scale. Parents provided feedback about the presentation, acceptability, wording, and order of items. Where possible, this feedback was incorporated into the final version of the scale. 
232 developing authors. Responses for each item were deemed either concordant or non-concordant,

233 based on the content of the Guidelines. Depending on the specific recommendation, some items

234 were given only one concordant response (e.g., for the false positive item "When [my teenager]

235 is upset, I encourage [him/her] to toughen up", only "never" was considered concordant).

236 However, we allowed more "lenient" scoring for items that may differ between families or

237 situations, but are still considered concordant with the Guidelines' recommendation (e.g., for the 238 item "I make time to ask [my teenager] about [his/her] day and what [he/she] has been doing",

239 answers of "often" or "sometimes" were considered concordant). Concordant item responses

240 were scored as 1 and non-concordant responses as 0 . We summed the item scores to yield nine

241 subscale scores and a total score. The total score can therefore range from 0 to 79 . Subscale

242 scores depend on the number of items in the subscale (see Table 2). A cut-off score was also set

243 to indicate concordance for each subscale (i.e., mastery of the skill area). These cut-off scores

244 were intentionally set to be high, so as to indicate close to absolute concordance with Guidelines.

245 We set this as our criterion for mastery, as the Guidelines are based on high quality research

246 evidence and international expert consensus. The recommendations are therefore the ultimate

247 goal which parents are encouraged to achieve. Concordance was set as one score less than $100 \%$

248 for all subscales except for the health habits subscale, which is the longest subscale (12 items).

249 This subscale has seven items on general health habits (diet, physical activity, sleep hygiene) and

250 five items on alcohol or drug use. We allowed a total of two non-concordant responses in this

251 subscale (cut-off score of 10). 
252 Table 2

253 PRADAS Subscales, Guidelines Topics Covered, Number of Items, Risk/Protective Factor

254 Assessed, and Example Items

\begin{tabular}{|c|c|c|c|c|}
\hline $\begin{array}{l}\text { PRADAS } \\
\text { subscale }\end{array}$ & $\begin{array}{l}\text { Guidelines topic } \\
\text { covered }\end{array}$ & $\begin{array}{l}\text { No. of } \\
\text { items }\end{array}$ & $\begin{array}{l}\text { Risk/protective } \\
\text { factors covered }\end{array}$ & Example items ${ }^{\mathrm{a}}$ \\
\hline $\begin{array}{l}\text { Parent-child } \\
\text { relationship }\end{array}$ & $\begin{array}{l}\text { Establish and } \\
\text { maintain } \\
\text { a good } \\
\text { relationship } \\
\text { with your teenager }\end{array}$ & 8 & $\begin{array}{l}\text { Parental warmth, } \\
\text { aversiveness, affection, } \\
\text { emotional availability }\end{array}$ & $\begin{array}{l}\text { I let my [my teenager] know that I love } \\
\text { [him/her]. } \\
\text { I can tell when [my teenager] is open to } \\
\text { talking with me. }\end{array}$ \\
\hline Involvement & $\begin{array}{l}\text { Be involved and } \\
\text { support increasing } \\
\text { autonomy }\end{array}$ & 8 & $\begin{array}{l}\text { Parental over- } \\
\text { involvement, autonomy } \\
\text { granting, monitoring }\end{array}$ & $\begin{array}{l}\text { I increase [my teenager]'s responsibilities } \\
\text { and independence over time (e.g. let } \\
\text { [him/her] make more decision about } \\
\text { [his/her] life). }\end{array}$ \\
\hline $\begin{array}{l}\text { Relationships } \\
\text { with others }\end{array}$ & $\begin{array}{l}\text { Encourage } \\
\text { supportive } \\
\text { relationships }\end{array}$ & 6 & $\begin{array}{l}\text { Parental encouragement } \\
\text { of sociability }\end{array}$ & $\begin{array}{l}\text { I encourage [my teenager] to spend time } \\
\text { with [his/her] friends. }\end{array}$ \\
\hline Family rules & $\begin{array}{l}\text { Establish family } \\
\text { rules and } \\
\text { consequences }\end{array}$ & 9 & $\begin{array}{l}\text { Consistency of } \\
\text { discipline }\end{array}$ & $\begin{array}{l}\text { Have you set specific, defined rules for } \\
\text { [your teenager]'s behaviour? } \\
\text { Was [your teenager] involved in } \\
\text { developing the family rules? }\end{array}$ \\
\hline $\begin{array}{l}\text { Home } \\
\text { environment }\end{array}$ & $\begin{array}{l}\text { Minimise conflict } \\
\text { in the home }\end{array}$ & 8 & $\begin{array}{l}\text { Inter-parental conflict, } \\
\text { parent-child conflict } \\
\text { management, criticism, } \\
\text { parental modelling of } \\
\text { conflict management }\end{array}$ & $\begin{array}{l}\text { If I argue with my partner, I make sure } \\
\text { that [my teenager] can't hear. } \\
\text { When I have an argument or conflict with } \\
\text { [my teenager], I problem solve the issue } \\
\text { with [him/her]. }\end{array}$ \\
\hline Health habits & $\begin{array}{l}\text { Encourage good } \\
\text { health habits }\end{array}$ & 12 & $\begin{array}{l}\text { Diet, physical activity, } \\
\text { sleep hygiene ( } 7 \text { items); } \\
\text { responding to alcohol or } \\
\text { drug use ( } 5 \text { items) }\end{array}$ & $\begin{array}{l}\text { I have good health habits (i.e. healthy } \\
\text { diet, regular exercise, responsible use of } \\
\text { alcohol) myself. } \\
\text { I allow my teenager to have an alcoholic } \\
\text { drink at home to help [him/her] learn to } \\
\text { drink responsibly. (False positive). }\end{array}$ \\
\hline $\begin{array}{l}\text { Dealing with } \\
\text { problems }\end{array}$ & $\begin{array}{l}\text { Help your } \\
\text { teenager to deal } \\
\text { with problems }\end{array}$ & 10 & $\begin{array}{l}\text { Problem solving, } \\
\text { emotion regulation, } \\
\text { stress management, } \\
\text { modeling of problem } \\
\text { solving approaches }\end{array}$ & $\begin{array}{l}\text { I encourage [my teenager] to work } \\
\text { towards realistic goals. } \\
\text { I give up on tasks that prove to be too } \\
\text { difficult. (False positive). }\end{array}$ \\
\hline $\begin{array}{l}\text { Coping with } \\
\text { anxiety }\end{array}$ & $\begin{array}{l}\text { Help your } \\
\text { teenager to deal } \\
\text { with anxiety }\end{array}$ & 9 & $\begin{array}{l}\text { Anxiety management } \\
\text { (avoidance, exposure), } \\
\text { modeling of anxiety } \\
\text { management strategies }\end{array}$ & $\begin{array}{l}\text { If my teenager takes steps to manage } \\
\text { [his/her] anxiety, I praise [him/her] for } \\
\text { doing it. }\end{array}$ \\
\hline $\begin{array}{l}\text { Professional } \\
\text { help-seeking }\end{array}$ & $\begin{array}{l}\text { Encourage } \\
\text { professional help- } \\
\text { seeking when } \\
\text { needed }\end{array}$ & 9 & $\begin{array}{l}\text { Professional help- } \\
\text { seeking knowledge and } \\
\text { behaviours (parent and } \\
\text { child) }\end{array}$ & $\begin{array}{l}\text { If you noticed a persistent change in [your } \\
\text { teenager]'s mood or behaviour, how } \\
\text { likely would you be to: } \\
\text { Encourage [him/her] to talk to you about } \\
\text { what's going on. } \\
\text { Take [him/her] to a trained mental health } \\
\text { professional. }\end{array}$ \\
\hline
\end{tabular}

a Square brackets in items denote personalisation with the adolescent's name and gender. 
In addition to the PRADAS items, we collected parent-reported information on parent

257

258

259

260

261

262

263

264

265

266

267

268

269

270

271

272

273

274

275

276 277 below acceptable for the alienation subscale (.69). cross-validation of the PRADAS are described below.

and child demographic characteristics, parent and child history of mental illness, and parental concern about their child's risk of developing depression and anxiety. Other measures used for

\section{Inventory of Parent and Peer Attachment - Parent-report (IPPA-P; Armsden \&}

Greenberg, 1987). The IPPA was originally developed as an adolescent-report measure of attachment to parents, measuring three cognitive-affective dimensions of attachment: mutual trust, quality of communication, and alienation in relationships. We administered an adapted 25item parent-report version of the scale (McElhaney et al., 2008; Allen, 2013, personal communication) to parents. Items were scored on a 5-point Likert scale (never true, seldom true, sometimes true, often true, almost always true). We calculated the three subscale scores (trust, communication, and alienation) as well as a total score. The original version of the inventory has demonstrated good internal consistency reliability (Cronbach's alpha .89 to .92) and three-week test-retest reliability (.93; Greenberg \& Armsden, 2009), as well as convergent validity with other scales of family functioning and environment (Armsden \& Greenberg, 1987; Gullone \& Robinson, 2005). The adapted version used in the current study has high correlations with the original version (.92 to .98), and acceptable to high Cronbach's alphas (.70 to .89 for total score, trust and communication subscales; .68 to .70 for the alienation subscale; Allen, 2013). A similar parent-report version has also been found to have high internal consistency (total score Cronbach's alpha $=.92 ;$ McElhaney et al., 2008). Cronbach's alphas for our sample were high for the total score (.90), acceptable for the trust (.87) and communication (.79) subscales, and just 
279 The EAC is a 45-item parent self-report inventory that assesses parental response to children's 280 expression of sadness, anger, and fear, according to five emotion socialisation strategies: support 281 (e.g., comforting or assisting the child); override (e.g., minimising the emotion); magnify (e.g., 282 amplifying the emotion); neglect (e.g., not responding); and punish (e.g., critical or punishing 283 responses). We calculated both the emotion-specific and global subscale scores, yielding a total 284 of 15 emotion-specific subscales and five global emotion socialisation subscales. The EAC has 285 previously demonstrated acceptable to good internal consistency reliability (Garside \& Klimes286 Dougan, 2002; Klimes-Dougan et al., 2007; O'Neal \& Magai, 2005; Silk et al., 2011) and 287 acceptable one-week test-retest reliability (Klimes-Dougan et al., 2001, as cited in Garside \& 288 Klimes-Dougan, 2002; O'Neal \& Magai, 2005). Internal consistency reliability for the current 289 sample was acceptable to high for the global emotion socialisation subscales (Cronbach's alphas: reward $=.88 ;$ punish $=.81 ;$ neglect $=.79 ;$ override $=.86 ;$ magnify $=.84)$. Six of the 15 emotionspecific subscales had Cronbach's alphas greater than .70, but the remaining nine ranged from .55 to .68 . We therefore opted to utilise the global emotion socialisation subscales in our 293 analyses. report (SCAS-C) and 39-item parent-report (SCAS-P) measure that assesses six domains of anxiety: separation anxiety, social phobia, obsessive-compulsive disorder, panic/agoraphobia,

297 generalised anxiety, and fear of physical injury. Respondents rate the degree to which the child 298 experiences a number of symptoms on a 4-point frequency scale (never, sometimes, often, always). Six of the child-report items are non-scored filler items designed to reduce response 300 bias. Items are scored from 0 (never) to 3 (always), and summed to form a total anxiety score. 
301 The SCAS total score has demonstrated high internal consistency reliability (Cronbach's alpha =

302.93 ) and adequate test-retest reliability between three and six months (.63 and .60, respectively)

303 in children aged 8 to 14 years (Spence, 1997; Spence, 1998; Spence, Barret \& Tuner, 2003). The

304 SCAS has also been normed on Australian school children aged 8 to 15 years, similar to the

305 current sample (Spence, 1998; Spence et al., 2003). We calculated the total score for parent- and

306 child-report versions, both of which had high internal consistency in our sample (Cronbach's

307 alphas: parent-report $=.91$; child-report $=.94$ ).

308 Short Mood and Feelings Questionnaire (SMFQ; Angold et al., 1995). The SMFQ is

309 a 13-item child- (SMFQ-C) and parent-report (SMFQ-P) scale assessing depressive symptoms in

310 children and adolescents. The scale is a shortened version of the original 32-item Mood and

311 Feelings Questionnaire (Angold et al., 1995). Respondents rate each item on a three-point scale

312 of 0 (not true), 1 (sometimes true) or 2 (true) to indicate the frequency of depressive symptoms in

313 the previous two weeks. The scale has been used widely in children aged 6 to 17 years, across

314 various samples including psychiatric, paediatric, and community populations (e.g., Angold et

315 al., 1995; Messer et al., 1995; Rhew et al., 2010; Thapar \& McGuffin, 1998). The SMFQ has

316 been shown to correlate highly with other widely-used measures of depression in children and

317 with structured clinical interviews (Angold et al., 1995; Kovacs, 1984). The scale has also shown

318 high internal consistency reliability (Cronbach's alphas $=.85$ for child-report, .87 for parent-

319 report), and good sensitivity and specificity for detecting cases of depression (Angold et al.,

320 1995). Cronbach's alphas for our sample were high (.90 for parent-report; .91 for child-report).

321 Data analysis. Proportion of missing data was low at both the subject and item level.

322 Less than $5 \%$ of cases had missing data on any particular measure. All items on the PRADAS

323 were mandatory due to the programming of the online parenting interventions, therefore all 
324 parents answered all items. Due to a technical error, four items had missing data for between one

325 and three participants. This was deemed to be missing completely at random and replaced using

326 Expectation Maximisation (EM) imputation. Overall proportion of missing data was less than

$3271 \%$ for all other measures. Missing data for the IPPA, EAC, SCAS and SMFQ were replaced

328 using EM for cases with less than $30 \%$ of data missing on any measure. Participants with

329 missing data greater than $30 \%$ on a measure were excluded from analyses.

330 Concordance with the Guidelines was initially examined with descriptive statistics for the

331 total and subscale scores. Frequencies were calculated for parent and child characteristics.

332 As the scale is a criterion-referenced measure, conventional internal consistency

333 reliability indices are not considered appropriate (Berk, 1980; Hambleton \& Rogers, 1990;

334 Subkoviak, 1988). Alternative reliability indices for criterion-referenced tests include the

335 agreement coefficient and the kappa coefficient (Hambleton \& Rogers, 1990; Subkoviak, 1988).

336 The agreement coefficient is a measure of the proportion of examinees consistently classified on

337 two or more administrations of a test; whereas the kappa coefficient reflects the gain in

338 consistency provided by using the test over an unreliable measure (Subkoviak, 1988). We chose

339 to utilise the agreement coefficient, as our purpose was to assess the overall consistency of the

340 measure in classifying parents as concordant or non-concordant with the Guidelines. Subkoviak

341 suggested that agreement coefficients of 0.75 or greater are acceptable in situations where half of

342 test-takers are masters and half are non-masters. Agreement coefficients increase as the

343 proportion of masters to non-masters becomes more dissimilar (Subkoviak, 1988). We utilised

344 the tables provided by Subkoviak to calculate an estimate of the agreement coefficient based on a

345 single administration of the measure, for the subscale scores and the total score. 
347 month follow-up assessment scores for a subset of participants $(N=175)$ in the waitlist control

348 group of one of the RCTs.

349 Validation of conventional norm-referenced tests typically involves structural modeling

350 techniques such as exploratory or confirmatory factor analysis to assess the extent to which items

351 represent underlying latent constructs. In contrast, criterion-referenced tests may assess a broad

352 range of skills within a given domain, all deemed necessary to achieve "mastery" of the domain.

353 The individual items comprising each domain may not be expected to reflect a single factor, as

354 items may represent distinct skills. As such, factor analyses of items may not be appropriate. In

355 the case of the current scale, the skills covered within each domain of the Guidelines were not

356 expected to uniformly represent nine distinct constructs or factors. Instead, we considered the

357 items to represent a set of skills that were deemed necessary to be concordant within a particular

358 parenting domain. As such, we did not employ conventional factor analytic techniques. Instead,

359 we were interested in the interrelationships between the domains and overall concordance with

360 the Guidelines. We examined the correlation matrix of subscale scores and the total score. We

361 predicted small to moderate correlations between the subscales, as each subscale was designed to

362 assess distinct parenting skills. As we expected concordance within one domain to be associated

363 with overall concordance, we predicted moderate to high correlations between the subscale

364 scores and total score.

365 To assess convergent validity of the scale, we examined correlations between the total

366 and subscale scores of our measure and those of the EAC and IPPA. Finally, we examined

367 bivariate correlations between parent and child characteristics (gender, age, education, mental

368 health history, scores on SCAS and SMFQ) and overall Guidelines concordance. We also 
369 conducted exploratory analyses to assess the ability of the PRADAS to distinguish between

370 participants above and below clinical cut-offs on the SCAS and SMFQ, using logistic

371 regressions.

372

Results

373 Parent and child mental health characteristics

374

Table 3 presents frequencies for parent and child history of mental health problems and parental concern about their adolescent's risk of developing depression or anxiety. Most parents expressed at least "a little" concern about their adolescent's risk of developing depression (79.9\%) or anxiety (79.0\%). Over half (58.5\%) of parent participants reported experiencing either past or current mental health problems themselves. Regarding adolescent mental health history, parents reported that $15.1 \%$ of adolescents had been diagnosed with a mental health problem in the past, and $22.1 \%$ believed that their child had experienced a mental health or

381 behavioural problem that had not been formally diagnosed. Similarly, $17.2 \%$ of adolescents were

382 reported to be experiencing current mental health issues, with $24.1 \%$ of parents concerned that

383 their child may be currently experiencing an undiagnosed mental health or behavioural problem. 


\section{Table 3}

385 Frequencies for Parental Concern about Adolescent Risk of Depression and Anxiety, and Parent 386 and Child History of Mental Health Problems

\begin{tabular}{|c|c|c|}
\hline Parent/child characteristic & $N$ & $\%$ \\
\hline \multicolumn{3}{|l|}{ Parental concern about child's risk of developing depression } \\
\hline Not at all & 139 & 19.5 \\
\hline A little & 338 & 47.5 \\
\hline Yes & 150 & 21.1 \\
\hline Very much so & 80 & 11.3 \\
\hline Missing (declined to answer) & 4 & 0.6 \\
\hline \multicolumn{3}{|l|}{ Parental concern about child's risk of developing an anxiety disorder } \\
\hline Not at all & 145 & 20.4 \\
\hline A little & 323 & 45.4 \\
\hline Yes & 151 & 21.1 \\
\hline Very much so & 89 & 12.5 \\
\hline Missing (declined to answer) & 3 & 0.4 \\
\hline \multicolumn{3}{|l|}{ Parental history or current mental health problem } \\
\hline None & 290 & 40.8 \\
\hline Yes, past history & 277 & 39.0 \\
\hline Yes, current & 75 & 10.5 \\
\hline Yes, past and current & 64 & 9.0 \\
\hline Missing (declined to answer) & 5 & 0.7 \\
\hline \multicolumn{3}{|l|}{ Child history of mental health or behavioural disorder diagnosis ${ }^{a}$} \\
\hline None & 425 & 59.8 \\
\hline Depression & 15 & 2.1 \\
\hline Any anxiety disorder & 50 & 7.0 \\
\hline Other mental health or behavioural disorder & 56 & 7.9 \\
\hline $\begin{array}{l}\text { No formal diagnosis, however I believe my child has experienced } \\
\text { some emotional or behavioural problems }\end{array}$ & 157 & 22.1 \\
\hline Missing (declined to answer) & 34 & 4.8 \\
\hline \multicolumn{3}{|l|}{ Child current mental health or behavioural problems ${ }^{a}$} \\
\hline None & 437 & 61.5 \\
\hline Depression & 24 & 3.4 \\
\hline Any anxiety disorder & 79 & 11.1 \\
\hline Other mental health or behavioural disorder & 55 & 7.7 \\
\hline $\begin{array}{l}\text { No formal diagnosis, however I believe my child is currently } \\
\text { experiencing some emotional or behavioural problems }\end{array}$ & 171 & 24.1 \\
\hline Missing (declined to answer) & 13 & 1.8 \\
\hline
\end{tabular}

387 Note. 'Other mental health or behavioural disorder' category includes: Autism Spectrum 388 Disorder, Attention-Deficit/Hyperactivity Disorder, Oppositional Defiant Disorder, Conduct 389 Disorder, learning difficulties, or any other disorder specified by parents.

390 a Percentages add to $>100 \%$ as multiple responses were allowed. 
391 Concordance with the Guidelines

392 Table 4 presents descriptive concordance statistics for the nine subscales and the total

393 score. Concordance rates for most subscales were low, with less than $20 \%$ of parents scoring

394 within the concordant range for seven of the nine subscales. This may in part be due to the fact

395 that cut-off scores for concordance were intentionally set to be high. Two subscales were notable

396 exceptions to this pattern: 1) Relationships with others had a much higher concordance rate of

$39777.5 \%$. The mean score of this subscale was close to the highest possible score (5.11 out of 6.00)

398 and there was less variance in responses, representing a ceiling effect; 2) Professional help-

399 seeking, which also had a higher concordance rate than other subscales, at $49.37 \%$.

$400 \quad$ Further exploration of items within the relationships with others subscale revealed ceiling

401 effects for four of the six items ( $94 \%$ to $99 \%$ of participants concordant), explaining the overall

402 ceiling effect. These items assessed parental encouragement of socialisation, being kind to

403 others, and talking to the adolescent about social problems (see Supplemental File 1 for scale

404 items). The remaining two items in this subscale, which were both negatively worded, had

405 concordance rates of $70.2 \%$ and $53.2 \%$.

406 Examination of the professional help-seeking subscale revealed ceiling effects for three

407 of the nine items. Two of these items assessed parental response to the question "If you noticed a

408 persistent change in your teenager's mood or behaviour, how likely would you be to: [insert

409 question]". 99\% of parents responded that they would encourage their teenager to speak to them

410 about what was going on, and $98.7 \%$ endorsed that they would try to determine whether the

411 change was caused by a temporary situation or more ongoing problem. Further, 93\% of parents

412 stated that they would know where to seek appropriate professional help for their teenager if

413 needed. Other items within this subscale had concordance rates between $45.9 \%$ and $83.1 \%$. 


\section{Table 4}

415 Descriptive and Reliability Statistics for PRADAS Subscales and Total Score $(N=711)$

\begin{tabular}{|c|c|c|c|c|c|c|c|c|}
\hline $\begin{array}{l}\text { PRADAS } \\
\text { subscale }\end{array}$ & $\begin{array}{l}\text { Highest } \\
\text { possible } \\
\text { score }^{\mathrm{a}}\end{array}$ & $\begin{array}{l}\text { Cut-off } \\
\text { score for } \\
\text { concordance }\end{array}$ & $\begin{array}{l}\text { Observed } \\
\text { minimum }\end{array}$ & $\begin{array}{l}\text { Observed } \\
\text { maximum }\end{array}$ & $M$ & $S D$ & $\begin{array}{l}\% \\
\text { concordant }\end{array}$ & $\begin{array}{l}\text { Agreement } \\
\text { coefficient }\end{array}$ \\
\hline $\begin{array}{l}\text { Parent-child } \\
\text { relationship }\end{array}$ & 8.00 & 7.00 & 0.00 & 8.00 & 5.00 & 1.27 & 11.67 & .84 \\
\hline Involvement & 8.00 & 7.00 & 1.00 & 8.00 & 5.26 & 1.28 & 17.86 & .77 \\
\hline $\begin{array}{l}\text { Relationships } \\
\text { with others }\end{array}$ & 6.00 & 5.00 & 2.00 & 6.00 & 5.11 & 0.80 & 77.50 & .68 \\
\hline Family rules & 9.00 & 8.00 & 1.00 & 9.00 & 4.57 & 1.69 & 4.36 & .98 \\
\hline $\begin{array}{l}\text { Home } \\
\text { environment }\end{array}$ & 8.00 & 7.00 & 0.00 & 8.00 & 4.23 & 1.67 & 9.85 & .89 \\
\hline Health habits & 12.00 & 10.00 & 3.00 & 12.00 & 7.65 & 1.68 & 13.22 & .81 \\
\hline $\begin{array}{l}\text { Dealing with } \\
\text { problems }\end{array}$ & 10.00 & 9.00 & 1.00 & 10.00 & 6.93 & 1.75 & 18.28 & .81 \\
\hline $\begin{array}{l}\text { Coping with } \\
\text { anxiety }\end{array}$ & 9.00 & 8.00 & 1.00 & 9.00 & 6.14 & 1.51 & 11.95 & .81 \\
\hline $\begin{array}{l}\text { Professional } \\
\text { help-seeking }\end{array}$ & 9.00 & 8.00 & 2.00 & 9.00 & 7.30 & 1.28 & 49.37 & .61 \\
\hline Total score & 79.00 & 69.00 & 18.00 & 72.00 & 52.21 & 7.59 & 0.42 & .97 \\
\hline $\begin{array}{l}\text { Revised total } \\
\text { score }^{b}\end{array}$ & 73.00 & 64.00 & 15.00 & 67.00 & 47.09 & 7.44 & 0.42 & .97 \\
\hline
\end{tabular}

$416{ }^{a}$ Lowest possible score for all (sub)scales is zero. Highest possible score is equal to the number 417 of items in each (sub)scale.

$418{ }^{b}$ Revised total score is the final total score, based on revisions discussed below. This score 419 excludes all items from the relationships with others subscale, which was removed from the final 420 version of the scale.

421

\section{Reliability of the scale}

423 Agreement coefficients for the subscales and the total score are presented in Table 4.

424 Agreement coefficients were above the recommended .75 level for seven subscales, and was 425 very high (.97) for the total score. Two subscales had lower reliability: relationships with others 
426 (.68); and professional help-seeking (.61). Reliability was therefore deemed to be high for the

427 total score, acceptable to high for seven of the subscales, and questionable for two subscales.

428 Test-retest reliability was calculated for a smaller subsample of 175 participants in the

429 waitlist control group of one of the RCTs, based on data from baseline to 1-month follow-up

430 assessments. Test-retest reliability was deemed to be acceptable for the total score, $r=.76, p<$

431.001 . Subscale test-retest reliability ranged from .29 to $.72(p<.001)$, with five of the nine

432 subscales having test-retest reliability between .59 and .72 (see Table S1 for individual subscale

433 test-retest reliability).

\section{Correlations between subscale scores and total score}

435 We examined the correlation matrix of subscale scores and the total score (see Table 5).

436 With the exception of the relationships with others subscale, all subscales had significant

437 moderate to high correlations with the total score, as predicted. Also as hypothesised, most

438 subscales had small to moderate correlations with the other subscales, reflecting the unique skills

439 assessed within each domain. The relationships with others subscale had the lowest correlations

440 with other subscales.

441 
442 Table 5

443 Pearson's Correlations between PRADAS Subscale Scores and PRADAS Total Score $(N=711)$ 444

\begin{tabular}{|c|c|c|c|c|c|c|c|c|c|}
\hline & 1 & 2 & 3 & 4 & 5 & 6 & 7 & 8 & 9 \\
\hline & Relatior & & & & & & & & \\
\hline 2. Involvement & $.35^{* * *}$ & - & & & & & & & \\
\hline $\begin{array}{l}\text { 3. Relationships } \\
\text { with others }\end{array}$ & $.09 *$ & $.21 * * *$ & - & & & & & & \\
\hline 4. Family rules & $.31 * * *$ & $.31 * * *$ & .03 & - & & & & & \\
\hline $\begin{array}{l}\text { 5. Home } \\
\text { environment }\end{array}$ & $.40^{* * *}$ & $.24 * * *$ & $.08^{*}$ & $.28 * * *$ & - & & & & \\
\hline 6. Health habits & $.19^{* * *}$ & $.22 * * *$ & .00 & $.23 * * *$ & $.18^{* * *}$ & - & & & \\
\hline $\begin{array}{l}\text { 7. Dealing with } \\
\text { problems }\end{array}$ & $.37 * * *$ & $.32 * * *$ & .06 & $.44 * * *$ & $.33 * * *$ & $.30 * * *$ & - & & \\
\hline $\begin{array}{l}\text { 8. Coping with } \\
\text { anxiety }\end{array}$ & $.29 * * *$ & $.26 * * *$ & $.12 * *$ & $.31 * * *$ & $.29 * * *$ & $.19 * * *$ & $.49^{* * *}$ & - & \\
\hline $\begin{array}{l}\text { 9. Professional } \\
\text { help-seeking }\end{array}$ & $.21 * * *$ & $.20 * * *$ & .07 & $.20 * * *$ & $.21 * * *$ & $.27 * * *$ & $.28 * * *$ & $.25^{* * *}$ & - \\
\hline Total score & $.62 * * *$ & $.58 * * *$ & $.23 * * *$ & $.64 * * *$ & $.61 * * *$ & $.53 * * *$ & $.73^{* * *}$ & $.64 * * *$ & $.51 * * *$ \\
\hline $\begin{array}{l}\text { Revised total } \\
\text { score }^{\mathrm{a}}\end{array}$ & $.62 * * *$ & $.57 * * *$ & $.13 * * *$ & $.65 * * *$ & $.61 * * *$ & $.54 * * *$ & $.74 * * *$ & $.64 * * *$ & $.51 * * *$ \\
\hline
\end{tabular}

${ }^{a}$ Revised total score is the final total score, based on revisions discussed below. This score excludes all items from the relationships with others subscale, which was removed from the final version of the scale.

\section{Refinement of the scale based on analyses}

Based on the above analyses, we chose to remove the relationships with others subscale

452 from the final version of the scale for the following reasons: 1) there was a ceiling effect for the

453 subscale score, attributable to ceiling effects for four of the six items; 2) questionable reliability

454 (agreement coefficient $=.68)$; and 3$)$ this section had a low correlation with the total score $(r=$

455.23 ; in contrast to all other subscales which had correlations $\geq .51$ ) as well as low correlations

456 with the other subscales ( $r \mathrm{~s} .00$ to .21 ). After removing the 6-item relationships with others 
457 subscale, the agreement coefficient for the total score was unchanged (.97) and the test-retest

458 reliability of the total score increased slightly (from .76 to .78).

459 Although the professional help-seeking subscale also had ceiling effects for three out of

460 nine items, this may be at least partially attributable to the demographic characteristics of our

461 sample, rather than the items. Most parents were highly educated, and had already taken a step

462 towards seeking professional help by enrolling in an RCT aimed at reducing risk of depression

463 and anxiety in their adolescent. Moreover, given that many parents and adolescents in our sample

464 had a history of mental health issues, it is likely that these parents had greater knowledge of

465 mental health support services than parents who have never had reason to access these. Further,

466 the subscale total score did not have a ceiling effect, and the subscale had a moderate correlation

467 with the total score. We therefore chose to retain this subscale, despite its lower reliability.

468 All subsequent analyses are based on the revised total score calculated without the items

469 comprising the relationships with others subscale.

\section{Convergent validity}

To examine convergent validity, correlations between the total and subscale scores of the

472 PRADAS and the IPPA and EAC were examined (see Table 6). We predicted positive

473 correlations with all IPPA scores, as the items from the alienation subscale were already reverse

474 scored. Four of the five EAC subscales (punish, neglect, override, magnify) assess undesirable

475 parenting practices and were not reverse scored, hence we predicted our measure to correlate

476 negatively with these subscales and positively with the reward subscale. In support of the

477 convergent validity of the PRADAS, there was a moderate to strong positive correlation between

478 the PRADAS total score and the IPPA total score $(r=.61, p<.001)$. The total score also had

479 moderate to strong correlations in the predicted directions with the trust and communication 
480 subscales of the IPPA $(r \mathrm{~s}=.56$ and $.61, p \mathrm{~s}<.001)$, as well as three of the five EAC global

481 subscales (reward, $r=.59$; punish, $r=-.49$; neglect $r=-.56$; all $p \mathrm{~s}<.001$ ). These subscales each

482 have some overlapping content with our scale, hence the strength of the correlations are

483 appropriate to the degree of overlap of constructs assessed. There were also small to moderate 484 correlations in the predicted direction with the IPPA alienation subscale $(r=.43, p<.001)$, as

485 well as the EAC override and magnify subscales $(r \mathrm{~s}=-.32$ and $-.36, p \mathrm{~s}<.001)$.

486 Examination of the correlations between the PRADAS subscale scores and subscales of

487 the IPPA and EAC also revealed small to moderate correlations in the predicted directions. For

488 example, the parent-child relationship subscale had a correlation of $.51(p<.001)$ with the IPPA

489 total score and trust subscale, and lower correlations with the communication and alienation

490 subscales $(r \mathrm{~s}=.45$ and $.35, p \mathrm{~s}<.001)$, as well as the EAC reward, punish, and neglect subscales

491 ( $r \mathrm{~s}=-.42$ to .46 , all $p \mathrm{~s}<.001)$. Likewise, the involvement, dealing with problems, and coping

492 with anxiety subscales all had small to moderate correlations in the predicted directions with

493 various subscales of the IPPA and EAC (see Table S2 for subscale correlations). Two subscales

494 of our measure assessed content not measured by the IPPA or the EAC: health habits and

495 professional help-seeking. As expected, these subscales had the lowest correlations with all

496 subscales of the IPPA and EAC (all $|r|<.32$; see Table S2). Overall, we interpreted these results

497 as support for the convergent validity of the PRADAS. 
498 Table 6

499 Correlations between PRADAS Revised Total Score and Scores on the IPPA and EAC

\begin{tabular}{lcc}
\hline & $N$ & $\begin{array}{c}\text { Pearson's correlation with PRADAS } \\
\text { revised total score }\end{array}$ \\
\hline IPPA total score & 709 & .61 \\
IPPA trust subscale & 709 & .56 \\
IPPA communication subscale & 709 & .61 \\
IPPA alienation subscale & 709 & .42 \\
EAC reward global subscale & 704 & .59 \\
EAC punish global subscale & 704 & -.49 \\
EAC neglect global subscale & 704 & -.56 \\
EAC override global subscale & 704 & -.32 \\
EAC magnify global subscale & 704 & -.36 \\
\hline
\end{tabular}

500 Note. IPPA = Inventory of Parent Peer Attachment, parent-report; EAC $=$ Emotions as a Child 501 Scale.

$502 p \mathrm{~s}<.001$ for all correlations.

503

504 Correlates of Guidelines concordance

505 Associations with adolescent symptoms. To examine the associations between parental

506 concordance with the Guidelines and adolescent symptoms of anxiety and depression, we

507 conducted bivariate correlations between the PRADAS revised total score and the parent- and

508 child-report versions of the SCAS and SMFQ (see Table 7). There were small significant

509 correlations in the predicted direction for both parent-report symptom measures, with higher

510 parental concordance with the Guidelines associated with lower parent-reported adolescent

511 symptoms. Correlations were very low, yet significant, for the child-report measures. The

512 correlations between parent- and child-report symptom measures were moderate (SCAS: $r=.45$,

$513 p<.001$; SMFQ: $r=.47, p<.001)$. 
514 To further explore the relationship between PRADAS scores and adolescent symptoms,

515 we conducted post hoc exploratory analyses of participants above and below clinical cut-offs on

516 the SCAS and SMFQ (see Supplemental File 2 for details). Binary logistic regressions were

517 performed to assess the ability of the PRADAS to predict elevated symptom status (i.e., above or

518 below clinical cut-off) on each of the measures. The logistic regression models were statistically

519 significant for the SCAS-P $\left(\chi^{2}[1]=12.77 p<.001,77.5 \%\right.$ correctly classified $)$, SMFQ-P $\left(\chi^{2}[1]\right.$

$520=21.88 p<.001,77.4 \%$ correctly classified $)$, and SMFQ-C $\left(\chi^{2}[1]=7.41 p=.006,69.8 \%\right.$

521 correctly classified), but not for the SCAS-C $\left(\chi^{2}[1]=3.50 p=.061,85.5 \%\right.$ correctly classified).

522 Effect sizes were small (Cohen's $d \mathrm{~s}=0.15$ to 0.31 ). Results of these analyses are presented in

523 Supplemental File 2, Table S3. 
524 Table 7

525 Correlations between PRADAS Revised Total Score, Parent- and Child-report SCAS and SMFQ

526 scores, and Parent and Child Characteristics

\begin{tabular}{|c|c|c|c|}
\hline & $\mathrm{N}$ & $\begin{array}{l}\text { Pearson's correlation with } \\
\text { PRADAS revised total } \\
\text { score }\end{array}$ & $p$ \\
\hline Parent-report SCAS & 708 & -.13 & $<.001$ \\
\hline Parent-report SMFQ & 708 & -.21 & $<.001$ \\
\hline Child-report SCAS & 660 & -.08 & .044 \\
\hline Child-report SMFQ & 658 & -.10 & .011 \\
\hline Parent male gender & 711 & -.13 & $<.001$ \\
\hline Child male gender & 711 & .04 & .355 \\
\hline Parent age & 711 & .06 & .086 \\
\hline Child age & 711 & -.05 & .187 \\
\hline Parent education level & 711 & .11 & .004 \\
\hline $\begin{array}{l}\text { Parental concern re: child's risk of } \\
\text { depression }\end{array}$ & 707 & -.14 & $<.001$ \\
\hline $\begin{array}{l}\text { Parent concern re: child's risk of } \\
\text { anxiety }\end{array}$ & 708 & -.11 & .005 \\
\hline Child current mental health problem & 698 & -.01 & .722 \\
\hline Child history of mental health diagnosis & 677 & -.02 & .694 \\
\hline $\begin{array}{l}\text { Parent history or current mental health } \\
\text { problem }\end{array}$ & 706 & -.05 & .224 \\
\hline
\end{tabular}

Note. SCAS = Spence Children's Anxiety Scale; SMFQ = Short Mood and Feelings

528 Questionnaire. Parent and child gender coded as $0=$ female, $1=$ male; parent education level

529 coded on an 6-point scale following Australian national education standards (higher values

530 represent higher levels of education; Australian Qualifications Framework Council, 2013);

531 parental concern about child's risk of depression and anxiety coded from $1=$ not at all concerned

532 to $4=$ very much concerned; child and parent mental health characteristics coded as $0=$ no

533 history/current mental health diagnosis (including parent-reported potential undiagnosed

534 problem), $1=$ history/current mental health diagnosis.

535

536

537
Associations with participant characteristics. Finally, we explored the correlations

between parent and child characteristics (gender, age, mental health history, parental concern 
539 about child's risk of depression/anxiety) and overall Guidelines concordance. As shown in Table

5407 , there were significant small positive correlations between overall Guidelines concordance and

541 parent female gender, higher parent education level, and lower parental concern about child's

542 risk of depression or anxiety. Parent or child age, child gender, and parent or child history of

543 mental health diagnosis were not correlated with Guidelines concordance.

\section{Discussion}

The primary aim of this study was to validate the newly developed Parenting to Reduce

Adolescent Depression and Anxiety Scale as a criterion-referenced measure of concordance with

547 a set of evidence-based guidelines, which recommend parenting strategies for the prevention of adolescent depression and anxiety. To do this, we examined the reliability and convergent validity of the measure. Our second aim was to examine levels of concordance with the Guidelines in a large sample of Australian parents of adolescents aged 12 to 15. Finally, we examined the correlates of concordance with the Guidelines in this sample.

We removed one subscale from the final version of the scale, due to a ceiling effect, questionable reliability, and low correlations with the total score and other subscale scores. The final version of the scale therefore comprises 73 items, which are summed to form eight subscale scores and a total score. The total score and seven of the eight subscales had high reliability, as measured by the agreement coefficient. One-month test-retest reliability of the total score was acceptable to

558 high, and varied for the subscale scores. Subscale scores had moderate to high correlations with 559 the total score, indicating that concordance in one area of the Guidelines is associated with 560 greater overall concordance. Most subscales had small to moderate correlations with the other 561 subscales, suggesting that while there is some association between domains, each subscale 
562 reflects a set of unique parenting skills. The total and subscale scores correlated in the predicted

563 direction and strength with the IPPA and EAC, supporting the convergent validity of the scale.

564 Based on our findings, we recommend that interpretation of scores on the PRADAS be

565 primarily based on the total score, which we found to be the most reliable and valid score. This

566 score gives an overall level of concordance with recommendations in the Guidelines, indicating

567 the degree to which a parent's current parenting practices align with the highest quality evidence

568 regarding parenting risk and protective factors for adolescent depression and anxiety. The eight

569 subscale scores may also provide valuable information, particularly if specific domains of

570 parenting skills are of interest. The subscales scores should, however, be interpreted in light of

571 the findings of their lower reliability. This is particularly the case for the professional help-

572 seeking subscale, which had questionable reliability. Results regarding this subscale may have

573 been influenced by our sample demographics, as parents were highly educated and had self-

574 selected to participate in an RCT of an online preventive parenting intervention. Further, parents

575 reported that they and their adolescents had slightly higher rates of current and past mental health

576 diagnoses than have been reported in national prevalence studies (e.g., Lawrence et al., 2015;

577 Slade et al., 2009). While our findings are based on parent-report of diagnosis, rather than

578 rigorous assessment measures, it is possible that parents chose to participate in the research

579 partially due to their own and/or their child's history of mental health issues. Future research

580 with the scale would benefit from collecting data from participants with varying levels of

581 education and mental health history.

\section{Parental concordance with the Guidelines}

We examined levels of parental concordance with established Guidelines in an Australian

584 community sample of parents of adolescents aged 12 to 15 years. Overall, parental concordance 
585 with the Guidelines was relatively low, with less than $20 \%$ of parents deemed concordant in six

586 of the eight domains. This is unsurprising given that we intentionally set high cut-off scores for

587 concordance. In contrast, the professional help-seeking domain had the highest concordance rate,

588 at $49 \%$. As discussed, this may be a result of our sample characteristics. Alternatively, parents

589 may have scored highly in this domain due to the hypothetical nature of the questions. The items

590 assess how likely a parent would be to respond in certain ways if they noticed a persistent change

591 in their adolescent's mood or behaviour, as well as how likely they would be to seek professional

592 help if needed. It is possible that parents may overestimate their likelihood to take particular

593 actions when posed in hypothetical scenarios. As posited by theories such as the Theory of

594 Planned Behaviour (Ajzen, 1991), and confirmed in numerous empirical studies (e.g., Armitage

595 \& Conner, 2001; McEachan et al., 2011; Sheeran, 2002), intentions do not always translate into 596 action.

597 Concordance was lowest (4\% of parents) for the family rules subscale, which assesses the 598 establishment and consistency of rules and consequences. Closer examination of item responses 599 revealed that less than half (47\%) of parents endorsed having set specific, defined rules for their 600 teenager's behaviour in most areas. Similarly, only $27 \%$ of parents answered that they had set 601 specific, defined consequences for breaking the rules, and 16\% said that their teenager had been 602 involved in developing most of the rules. Promisingly, most parents (86\%) stated that they adapt 603 the family rules to their teenager's maturity and responsibility, and $80 \%$ said that they speak with 604 their teenager about why their behaviour is not acceptable when enforcing a consequence. These 605 findings are consistent with findings from a similar measure designed to assess parental 606 concordance with guidelines for the prevention of adolescent alcohol misuse (Yap, Jorm \& 607 Lubman, 2015). This measure also assessed consistency of family rules, and found the family 
608 rules subscale to have the lowest concordance rate (7.2\%). Together, these findings highlight an

609 important target for future preventive programs, particularly given that parental disciplinary

610 practices are associated with risk for both internalising and externalising disorders (Berg-Nielsen

611 et al., 2002; Gryczkowski et al., 2010; Yap et al., 2014a).

612 The remaining six domains had concordance rates between approximately $10 \%$ and $20 \%$

613 of parents. Although this small percentage of parents scored above the cut-off score for

614 concordance with the entire domain, it is promising to note that mean subscale scores were close

615 to or above the mid-range of possible scores. In other words, most parents answered within the

616 concordant range for at least half of the individual items comprising each subscale, although they

617 did not reach the threshold set for mastery of the skill area. This was also the case for the total

618 score, which had a mean of 47 out of a possible 73 . This means that while very few parents were

619 considered concordant according to the cut-off scores set for "mastery" of each domain, on

620 average parents were adhering to over half of the recommendations in the Guidelines. It is

621 therefore plausible that many parents, particularly those who scored close to the cut-off, may

622 move into the concordant range with intervention, where parents are supported to make changes

623 in these parenting skill areas.

624 It could be argued that the designation of cut-off scores for concordance was somewhat

625 arbitrary, and that the cut-off scores could be set lower given the low concordance rates obtained

626 in our sample. As discussed, we chose high cut-off scores that indicate close-to-absolute-

627 concordance with the Guidelines' recommendations. This was based on the expertise of the

628 developing authors, the strong evidence base for the parenting factors assessed, and the purpose

629 for which the scale was initially developed. The optimal cut-off scores for a criterion-referenced

630 test such as this will depend on individual applications. For example, high cut-off scores may be 
631 appropriate when the goal is to evaluate intervention effects or to identify areas for improvement,

632 whereas lower cut-off scores may be appropriate if attempting to determine a "bare minimum"

633 level of competency. In the case of the PRADAS, we aimed to develop a measure that could be

634 used to identify domains of parenting that could be improved by parents so they become more

635 concordant with the Guidelines. From a public health perspective, prevention approaches that

636 attempt to shift all individuals along the continuum of risk are likely to have greater effects at a

637 population level than approaches only targeting those at highest risk (in this case, parents with

638 the lowest PRADAS scores; e.g., see seminal work by Rose, 1993). To explore this, we

639 examined scatterplots of PRADAS scores and scores on the symptoms measures with locally

640 weighted smoothing (LOESS) lines fitted. These curves indicated that, even at the higher end of

641 PRADAS scores, adolescent symptoms were lower, supporting the value of encouraging all

642 parents (even those with moderate and high scores) to increase their concordance with the

643 Guidelines. Finally, we conducted additional exploratory analyses with lower cut-off scores (one

644 score less than the original cut-offs for all subscales). With these lower cut-off scores, reliability

645 of the eight subscales and the total score reduced. Together, these findings support the use of

646 high cut-off scores for the current purpose of the PRADAS. It should also be noted that the cut-

647 off scores for concordance are one of two methods of interpreting PRADAS scores. The

648 continuous scores are also calculated (i.e., total score out of 73, or subscale scores), and these

649 can be interpreted alone or with reference to the subscale cut-off score. In many settings, the

650 continuous scores are likely to be of most interest, as they allow interpretation of an individual's

651 score in comparison to the range of possible scores. This may be of particular value in clinical

652 contexts, as well as to track change over time. 


\section{Correlates of parental concordance with the Guidelines}

654 We examined correlations between parental concordance with the Guidelines and parent-

655 and child-report measures of adolescent depression and anxiety symptoms, as well as participant

656 characteristics. We found small but statistically significant correlations between parental

657 Guidelines concordance and adolescent symptoms. The correlations were slightly larger for

658 parent-reported symptoms compared to child-reported symptoms, suggesting that parents who

659 rate themselves as more concordant with the Guidelines also report their adolescents to have

660 fewer symptoms of depression and anxiety. Additional exploratory logistic regression analyses

661 revealed a small effect of the PRADAS in predicting current symptom elevation status (i.e.,

662 above or below clinical cut-off) for three of the four symptom measures (SCAS-P, SMFQ-P,

663 SMFQ-C). To follow up on these findings, we also compared mean PRADAS scores for

664 participants above and below clinical cut-offs. In line with the logistic regression results,

665 PRADAS total scores were significantly lower for participants who scored above the clinical cut-

666 off on the SCAS-P, SMFQ-P and SMFQ-C (see Table S4). Together, these findings suggest that

667 there is a relationship between PRADAS scores and current clinically elevated symptom status,

668 albeit a modest one. Similarly, there was a small, significant correlation between Guidelines

669 concordance and parental concern about their child's risk of developing both depression and

670 anxiety. Parents with higher concordance were less concerned about their child's mental health.

671 The findings regarding adolescent symptoms should be interpreted with caution, due to the small

672 effects obtained and design of the study. The cross-sectional analyses limits our ability to assess

673 the theorised longer-term risk factors that the PRADAS is designed to assess. That is, the factors

674 assessed by the scale are expected to increase or decrease risk of depression or anxiety problems

675 developing throughout adolescence. More rigorous assessment of the relationship between 
676 PRADAS scores and adolescent symptoms requires prospectively collected data, which would

677 more accurately assess the predictive validity of the scale. Additionally, the symptom measures

678 could be considered "state" measures (i.e., assessing current/recent symptoms), whereas the

679 PRADAS may be more likely to capture "trait" level parenting practices. A cross-sectional

680 design may not adequately capture the relationship between these variables. Also, we

681 intentionally recruited a community sample, yielding mean scores on the symptom measures that

682 were below clinical cut-offs. It would be of interest to examine the associations between

683 PRADAS scores and symptom levels in a clinical population. Finally, meta-analyses of the

684 associations between parenting and child/adolescent symptoms have also reported small effect

685 sizes (e.g., McLeod, Weisz \& Wood, 2007; McLeod, Wood \& Weisz, 2007; Yap et al., 2014).

686 Given these points, it is unsurprising that the associations between PRADAS scores and

687 symptom measures were small.

688 Regarding demographic characteristics, there were small significant correlations of parent

689 female gender and higher levels of education with higher Guidelines concordance. This should

690 be interpreted in light of the over-representation of female, highly-educated parents in our

691 sample. This is in line with previous findings of higher rates of mental disorders among children

692 of parents with lower education (e.g., Lawrence et al., 2015; Meltzer et al., 2003; Merikangas et

693 al., 2010), as well as an association between parental education level and treatment outcomes in

694 parenting intervention studies (e.g., Reyno \& McGrath, 2006). Additionally, in a survey of

695 Australian parents' beliefs about the role of parenting in the prevention of depression in young

696 people, parents with tertiary-level education were more likely to hold beliefs consistent with the

697 evidence regarding parental over-control as a risk factor for depression (Yap \& Jorm, 2012). The

698 current findings contribute further evidence highlighting the need to consider socio-demographic 
699 factors, such as parental education level, when considering strategies to target in preventive

700 parenting programs.

701 Limitations and future directions

702 The current findings should be interpreted in the context of study limitations. Our sample

703 had an overrepresentation of highly-educated mothers from intact families, limiting the

704 generalisability of findings to fathers, those with lower levels of education, and different family

705 situations. Nonetheless, while our sample may not be representative of the general population, it

706 is likely representative of parents who self-select to participate in online parenting programs. Our

707 sample characteristics are similar to those often reported in online parenting intervention studies

708 (e.g., Dittman et al., 2014; Enebrink et al., 2012; March et al., 2009; Sanders et al., 2012).

709 Importantly, given the correlation found between education and parental Guidelines

710 concordance, concordance rates in our sample may be higher than would be found in less

711 educated populations. It is an important, yet challenging, direction for future research to recruit

712 more diverse samples of parents into research of this nature.

713 The current study is the first psychometric evaluation of the newly developed PRADAS.

714 Use of the PRADAS in future research will allow for further refinement of the measure. This

715 would be particularly valuable to improve the utility of the subscale scores, so as to provide eight

716 short scales that can be used with confidence to assess the various domains of parenting covered

717 in the Guidelines. The current form of the scale is quite long, with 73 items, and mean

718 completion time just under 18 minutes $(\mathrm{M}=17.76, \mathrm{SD}=12.93)$. It would therefore be valuable

719 to develop a short-form of the scale, which could have greater utility in clinical settings.

720 Additionally, development of an adolescent-report version of the PRADAS would allow cross- 
721 validation between parent- and adolescent-report, which is not captured in the current version of

722 the scale.

723 The associations between PRADAS scores and adolescent symptoms were small. The

724 cross-sectional nature of the study limits our ability to assess the prospective predictive validity

725 of the scale. We are also unable to ascertain concurrent validity based on diagnostic status, which

726 cannot be determined from symptom measures such as those used in the used in the current

727 study. However, it should be noted that the PRADAS is designed to assess parenting factors

728 which evidence and expert consensus suggest would influence risk of adolescent depression and

729 anxiety; the measure in itself does not purport to predict future risk. Results of the PRADAS

730 should therefore not be interpreted as indicative of risk for the adolescent.

731 To our knowledge, the PRADAS is the first assessment measure to comprehensively

732 assess the range of parenting risk and protective factors shown to influence the development of

733 depression and anxiety disorders in adolescents. This is a valuable addition to the growing body

734 of research investigating prevention of depression and anxiety in young people. It has potential

735 for use in both research and clinical settings. The scale may serve as an assessment measure to

736 tailor and evaluate preventive interventions targeting parenting factors, such as in the RCTs

737 mentioned above. For investigators interested in specific domains of parenting, the option of

738 eight subscales assessing different risk and protective factors may be of particular interest.

739 Clinically, the PRADAS could be used to identify individual parents' strengths and areas for

740 improvement, which may be valuable to clinicians working with parents. Future studies could

741 examine parental Guidelines concordance in clinical versus community samples, including

742 parents of adolescents receiving treatment for depression or anxiety. It would be of interest to

743 ascertain whether the same parenting factors are relevant to treatment or relapse prevention 
744 outcomes in a clinical population. If the PRADAS was found to contribute valuable information

745 in this population, it could be used to tailor interventions for parents of adolescents experiencing

746 depression or anxiety disorders.

\section{Conclusions}

748 This paper presented the development and validation of the Parenting to Reduce

749 Adolescent Depression and Anxiety Scale - a self-report, criterion-referenced measure that

750 assesses parental concordance with a set of evidence-based parenting guidelines for the

751 prevention of adolescent depression and anxiety disorders. Our findings provide preliminary

752 support for the reliability and validity of the scale as a measure of parental concordance with the

753 Guidelines, which reflect high-quality research evidence and expert consensus regarding

754 parenting risk and protective factors for adolescent depression and anxiety. Its ease of use and

755 coverage of a broad range of parenting factors make the PRADAS a valuable measure for both

756 clinical and research settings. It can be used to identify individual parents' strengths and areas for

757 improvement, or as an evaluative measure in studies of preventive interventions targeting

758 modifiable parenting factors for adolescent depression and anxiety disorders.

759

760 Acknowledgments

761 The authors would like to acknowledge the RCT project managers Mrs Jennifer Hanson-

762 Peterson, Dr Shireen Mahtani, Ms Claire Nicolas, and Ms Jacqueline Green, as well as the team

763 of research assistants who assisted with data collection. We would like to thank the parents in

764 our reference group for their input into the development of the PRADAS. We also acknowledge

765 beyondblue for their partnership in developing and disseminating the Guidelines, and Mental

766 Health First Aid Australia and the schools who assisted with recruitment for the two RCTs. 
768

769

770

771

772

773

774

775

776

777

778

779

780

781

782

783

784

785

786

787

788

789

790

791

792

793

794

795

796

Ajzen I. 1991. The theory of planned behavior. Organizational Behavior and Human Decision Processes, 50:179-211. DOI: 10.1016/0749-5978(91)90020-T

Angold A, Costello E, Messer S, Pickles A, Winder F, \& Silver D. 1995. Development of a short questionnaire for use in epidemiological studies of depression in children and adolescents. International Journal of Methods in Psychiatric Research, 5:237-249.

Armitage CJ \& Conner M. 2001. Efficacy of the theory of planned behaviour: A meta-analytic review. British Journal of Social Psychology, 40:471-499. DOI: $10.1348 / 014466601164939$

Armsden GC \& Greenberg MT. 1987. The inventory of parent and peer attachment: Individual differences and their relationship to psychological well-being in adolescence. Journal of Youth and Adolescence, 16:427-454. DOI: 10.1007/BF02202939

Allen, JP. 2013. Unpublished data on the Inventory of Parent and Peer Attachment. Personal communication, 2013.

Australian Qualifications Framework Council, 2013. Australian Qualifications Framework: Second Edition. South Australia: Australian Government Department of Education and Training. Retrieved January 2017 from: https://www.aqf.edu.au/

Avenevoli S \& Merikangas KR. 2006. Implications of high-risk family studies for prevention of depression. American Journal of Preventive Medicine, 31:126-135. DOI: 10.1016/j.amepre.2006.07.003

Berg-Nielsen TS, Vikan A, \& Dahl AA. 2002. Parenting related to child and parental psychopathology: A descriptive review of the literature. Clinical Child Psychology and Psychiatry, 7:529-552. DOI: 10.1177/1359104502007004006

Berk RA. 1980. A consumers' guide to criterion-referenced test reliability. Journal of Educational Measurement, 17:323-349.

Copeland WE, Shanahan L, Costello EJ, \& Angold A. 2009. Childhood and adolescent psychiatric disorders as predictors of young adult disorders. Archives of General Psychiatry, 66:764-772. DOI: 10.1001/archgenpsychiatry.2009.85

Dekker MC, Ferdinand RF, Van Lang ND, Bongers IL, Van Der Ende J, \& Verhulst FC. 2007. Developmental trajectories of depressive symptoms from early childhood to late 
797

798

799

800

801

802

803

804

805

806

807

808

809

810

811

812

813

814

815

816

817

818

819

820

821

822

823

824

825

826

827

adolescence: Gender differences and adult outcome. Journal of Child Psychology and Psychiatry, 48:657-666. DOI: 10.1111/j.1469-7610.2007.01742.x

Dittman CK, Farruggia SP, Palmer ML, Sanders MR, \& Keown LJ. 2014. Predicting success in an online parenting intervention: The role of child, parent, and family factors. Journal of Family Psychology, 28:236. DOI: 10.1037/a0035991

Enebrink P, Högström J, Forster M, \& Ghaderi A. 2012. Internet-based parent management training: A randomized controlled study. Behaviour Research and Therapy, 50:240-249. DOI: 10.1016/j.brat.2012.01.006

Fisak Jr BJ, Richard D, \& Mann A. 2011. The prevention of child and adolescent anxiety: A meta-analytic review. Prevention Science, 12:255-268. DOI: 10.1007/s11121-011-0210-0

Garber J. 2006. Depression in children and adolescents: Linking risk research and prevention. American Journal of Preventive Medicine, 31:104-125. DOI: 10.1016/j.amepre.2006.07.007

Garside RB \& Klimes-Dougan B. 2002. Socialization of discrete negative emotions: Gender differences and links with psychological distress. Sex Roles, 47:115-128. DOI: 10.1023/A:1021090904785

Greenberg MT \& Armsden GC. 2009. Manual for the Inventory of Parent and Peer Attachment. Seattle, WA: University of Washington.

Gryczkowski MR, Jordan SS, \& Mercer SH. 2010. Differential relations between mothers' and fathers' parenting practices and child externalizing behavior. Journal of Child and Family Studies, 19:539-546. DOI: 10.1007/s10826-009-9326-2

Gullone E \& Robinson K. 2005. The Inventory of Parent and Peer Attachment-Revised (IPPA-R) for children: A psychometric investigation. Clinical Psychology \& Psychotherapy, 12:67-79. DOI: 10.1002/cpp.433

Hambleton RK \& Rogers J. 1990. Advances in Criterion-Referenced Measurement. In: Hambleton RK, and Neal JN, eds. Advances in Educational and Psychological Testing: Theory and Applications. 1 ed. New York: Springer.

Hankin BL. 2006. Adolescent depression: Description, causes, and interventions. Epilepsy \& Behavior, 8:102-114. DOI: 10.1016/j.yebeh.2005.10.012

Kessler RC, Angermeyer M, Anthony JC, de Graaf R, Demyttenaere K, Gasquet I, de Girolamo G, Gluzman S, Gureje O, \& Haro JM. 2007. Lifetime prevalence and age-of-onset 
828

829

830

831

832

833

834

835

836

837

838

839

840

841

842

843

844

845

846

847

848

849

850

851

852

853

854

855

856

857

distributions of mental disorders in the World Health Organization's World Mental Health Survey Initiative. World Psychiatry, 6:168-176.

Kessler RC, Chiu WT, Demler O, \& Walters EE. 2005. Prevalence, severity, and comorbidity of 12-month DSM-IV disorders in the National Comorbidity Survey Replication. Archives of General Psychiatry, 62:617-627. DOI: 10.1001/archpsyc.62.6.617

Klimes-Dougan B, Brand AE, \& Garside RB. 2001. Factor structure, reliability, and validity of an emotion socialization scale. In: O'Neal CR, editor. The Annual Meeting of the American Psychological Association. San Francisco, CA.

Klimes-Dougan B, Brand AE, Zahn-Waxler C, Usher B, Hastings PD, Kendziora K, \& Garside RB. 2007. Parental emotion socialization in adolescence: Differences in sex, age and problem status. Social Development, 16:326-342. DOI: 10.1111/j.14679507.2007.00387.x

Kovacs M. 1984. The Children's Depression, Inventory (CDI). Psychopharmacology Bulletin, 21:995-998.

Lawrence D, Johnson S, Hafekost J, de Haan KB, Sawyer M, Ainley J, \& Zubrick SR. 2015. The mental health of children and adolescents: Report on the second Australian Child and Adolescent Survey of Mental Health and Wellbeing. Department of Health, Canberra: Australian Government Department of Health.

March S, Spence SH, \& Donovan CL. 2009. The efficacy of an internet-based cognitivebehavioral therapy intervention for child anxiety disorders. Journal of Pediatric Psychology, 34:474-487. DOI: 10.1093/jpepsy/jsn099

Mathew A, Pettit J, Lewinsohn P, Seeley J, \& Roberts R. 2011. Co-morbidity between major depressive disorder and anxiety disorders: Shared etiology or direct causation? Psychological Medicine, 41:2023-2034. DOI: 10.1017/S0033291711000407

Mathews R, Hall WD, Vos T, Patton GC, \& Degenhardt L. 2011. What are the major drivers of prevalent disability burden in young Australians. The Medical Journal of Australia, 194:232-235.

McEachan RRC, Conner M, Taylor NJ, \& Lawton RJ. 2011. Prospective prediction of healthrelated behaviours with the theory of planned behaviour: A meta-analysis. Health Psychology Review, 5:97-144. 
858 McElehany KB, Porter MP, Thomson LW, \& Allen, JP. Apples and oranges: Divergent meaning

859

860

861

862

863

864

865

866

867

868

869

870

871

872

873

874

875

876

877

878

879

880

881

882

883

884

885

886

887

888

of parents' and adolescents' perceptions of parental influence. Journal of Early Adolescence, 28:206-299. DOI: 10.1177/0272431607312768

McLeod, BD, Weisz, JR \& Wood, JJ. 2007. Examining the association between parenting and childhood depression: A meta-analysis. Clinical Psychology Review, 27: 986-1003. DOI: 10.1016/j.cpr.2007.03.001

McLeod, BD, Wood, JJ \& Weisz, JR. 2007. Examining the association between parenting and childhood anxiety: A meta-analysis. Clinical Psychology Review, 27: 155-172. DOI: 10.1016/j.cpr.2006.09.002

Meltzer H, Gatward R, Goodman R, \& Ford T. 2003. Mental health of children and adolescents in Great Britain. International Review of Psychiatry, 15:185-187. DOI: 10.1080/0954026021000046155

Merikangas KR, He J-P, Burstein M, Swanson SA, Avenevoli S, Cui L, Benjet C, Georgiades K, \& Swendsen J. 2010. Lifetime prevalence of mental disorders in US adolescents: results from the National Comorbidity Survey Replication-Adolescent Supplement (NCS-A). Journal of the American Academy of Child \& Adolescent Psychiatry, 49:980-989. DOI: 10.1016/j.jaac.2010.05.017

Messer S, Angold A, Costello E, Loeber R, Van Kammen W, \& Stouthamer-Loeber M. 1995. Development of a short questionnaire for use in epidemiological studies of depression in children and adolescents: Factor composition and structure across development. International Journal of Methods in Psychiatric Research, 5:251-262.

O'Neal CR \& Magai C. 2005. Do parents respond in different ways when children feel different emotions? The emotional context of parenting. Development and Psychopathology, 17:467-487. DOI: 10.1017/S0954579405050224

Parenting Strategies Program. 2013. How to prevent depression and clinical anxiety in your teenager: Strategies for parents. Melbourne: Beyondblue.

Parker G, Tupling H, \& Brown L. 1979. A parental bonding instrument. British Journal of Medical Psychology, 52:1-10. DOI: 10.1111/j.2044-8341.1979.tb02487.x

Patel V, Flisher AJ, Hetrick S, \& McGorry P. 2007. Mental health of young people: A global public-health challenge. The Lancet, 369:1302-1313. DOI: 10.1016/s01406736(07)60368-7

PeerJ reviewing PDF | (2017:05:18077:2:0:CHECK 23 Aug 2017) 
889 Perris C, Jacobsson L, Linndström H, Knorring L, \& Perris H. 1980. Development of a new

890

891

892

893

894

895

896

897

898

899

900

901

902

903

904

905

906

907

908

909

910

911

912

913

914

915

916

917 inventory for assessing memories of parental rearing behaviour. Acta Psychiatrica Scandinavica, 61:265-274. DOI: 10.1111/j.1600-0447.1980.tb00581.x

Rapee RM. 2012. Family factors in the development and management of anxiety disorders. Clinical Child and Family Psychology Review, 15:69-80. 10.1007/s10567-011-0106-3

Rapee RM, Schniering CA, \& Hudson JL. 2009. Anxiety disorders during childhood and adolescence: Origins and treatment. Annual Review of Clinical Psychology, 5:311-341. DOI: 10.1146/annurev.clinpsy.032408.153628

Restifo K \& Bögels S. 2009. Family processes in the development of youth depression: Translating the evidence to treatment. Clinical Psychology Review, 29:294-316. DOI: 10.1016/j.cpr.2009.02.005

Reyno SM \& McGrath PJ. 2006. Predictors of parent training efficacy for child externalizing behavior problems - a meta-analytic review. Journal of Child Psychology and Psychiatry, 47:99-111. DOI: 10.1111/j.1469-7610.2005.01544.x

Rhew IC, Simpson K, Tracy M, Lymp J, McCauley E, Tsuang D, \& Stoep AV. 2010. Criterion validity of the Short Mood and Feelings Questionnaire and one-and two-item depression screens in young adolescents. Child and Adolescent Psychiatry and Mental Health, 4:111. DOI: $10.1186 / 1753-2000-4-8$

Rose, G. 1993. Mental disorder and strategies of prevention. Psychological Medicine, 23, 553555. DOI: $10.1017 / \mathrm{S} 0033291700025320$

Sanders MR, Baker S, \& Turner KM. 2012. A randomized controlled trial evaluating the efficacy of Triple P Online with parents of children with early-onset conduct problems. Behaviour Research and Therapy, 50:675-684. DOI: 10.1016/j.brat.2012.07.004

Sandler IN, Schoenfelder, EN, Wolchik, SA, \& MacKinnon, DP. 2011. Long-term impact of prenetion programs to promote effective parenting: Lasting effects but uncertain processes. Annual Review of Psychology, 62:299-329. DOI:

10.1146/annurev.psych.121208.131619.

Siegenthaler, E, Munder, T, \& Egger, M. 2012. Effect of preventive interventions in mentally ill parents on the mental health of the offspring: Systematic review and meta-analysis. 
918

919

920

921

922

923

924

925

926

927

928

929

930

931

932

933

934

935

936

937

938

939

940

941

942

943

944

945

946

947

948

Journal of the American Academy of Child and Adolescent Psychiatry, 1:8-17. DOI: 10.1016/j.jaac.2011.10.018

Schaefer ES. 1965. Children's reports of parental behavior: An inventory. Child Development, 413-424.

Sheeran P. 2002. Intention-behavior relations: A conceptual and empirical review. European Review of Social Psychology, 12:1-36. DOI: 10.1080/14792772143000003

Silk JS, Shaw DS, Prout JT, O'Rourke F, Lane TJ, \& Kovacs M. 2011. Socialization of emotion and offspring internalizing symptoms in mothers with childhood-onset depression. Journal of Applied Developmental Psychology, 32:127-136. DOI: 10.1016/j.appdev.2011.02.001

Slade T, Johnston A, Oakley Browne MA, Andrews G, \& Whiteford H. 2009. 2007 National survey of mental health and wellbeing: Methods and key findings. Australian and New Zealand Journal of Psychiatry, 43:594-605.

Spence SH. 1997. Structure of anxiety symptoms among children: A confirmatory factoranalytic study. Journal of Abnormal Psychology, 106:280-297.

Spence SH. 1998. A measure of anxiety symptoms among children. Behaviour Research and Therapy, 36:545-566.

Spence SH, Barrett PM, \& Turner CM. 2003. Psychometric properties of the Spence Children's Anxiety Scale with young adolescents. Journal of Anxiety Disorders, 17:605-625.

Subkoviak MJ. 1988. A practitioner's guide to computation and interpretation of reliability indices for mastery tests. Journal of Educational Measurement, 25:47-55.

Thapar A \& McGuffin P. 1998. Validity of the shortened Mood and Feelings Questionnaire in a community sample of children and adolescents: A preliminary research note. Psychiatry Research, 81:259-268.

Van Voorhees BW, Paunesku D, Kuwabara SA, Basu A, Gollan J, Hankin BL, Melkonian S, \& Reinecke M. 2008. Protective and vulnerability factors predicting new-onset depressive episode in a representative of US adolescents. Journal of Adolescent Health, 42:605-616. DOI: $10.1016 /$ j.jadohealth.2007.11.135

Woodward LJ \& Fergusson DM. 2001. Life course outcomes of young people with anxiety disorders in adolescence. Journal of the American Academy of Child \& Adolescent Psychiatry, 40:1086-1093. DOI: 10.1097/00004583-200109000-00018 
949 Yap MB, Morgan AJ, Cairns K, Jorm AF, Hetrick SE, \& Merry S. 2016. Parents in prevention:

950

951

952

953

954

955

956

957

958

959

960

961

962

963

964

965

966

967

968

969

970 A meta-analysis of randomized controlled trials of parenting interventions to prevent internalizing problems in children from birth to age 18. Clinical Psychology Review, 50:138-158. DOI: 10.1016/j.cpr.2016.10.003

Yap MBH, Jorm A, Bazley R, Kelly C, Ryan S, \& Lubman D. 2011. Web-based parenting program to prevent adolescent alcohol misuse: Rationale and development. Australasian Psychiatry, 19:339-344. DOI: 10.3109/10398562.2011.603334

Yap MBH \& Jorm AF. 2012. Parents' beliefs about actions they can take to prevent depressive disorders in young people: Results from an Australian national survey. Epidemiology and Psychiatric Sciences, 21:117-123. DOI: 10.1017/S2045796011000667

Yap MBH \& Jorm AF. 2015. Parental factors associated with childhood anxiety, depression, and internalizing problems: A systematic review and meta-analysis. Journal of Affective Disorders, 175:424-440. DOI: 10.1016/j.jad.2015.01.050

Yap MBH, Jorm AF, \& Lubman DI. 2015. What are parents doing to reduce adolescent alcohol misuse? Evaluating concordance with parenting guidelines for adolescent alcohol use. BMC Public Health, 15:114. DOI: 10.1186/s12889-015-1452-8

Yap MBH, Pilkington PD, Ryan SM, \& Jorm AF. 2014a. Parental factors associated with depression and anxiety in young people: A systematic review and meta-analysis. Journal of Affective Disorders, 156:8-23. DOI: 10.1016/j.jad.2013.11.007

Yap MBH, Pilkington PD, Ryan SM, Kelly CM, \& Jorm AF. 2014b. Parenting strategies for reducing the risk of adolescent depression and anxiety disorders: A Delphi consensus study. Journal of Affective Disorders, 156:67-75. DOI: 10.1016/j.jad.2013.11.017 